\title{
Finding an academic space: reflexivity among sustainability researchers
}

\author{
Åsa Knaggård $^{1,2}$, Barry Ness $^{2,3}$ and David Harnesk ${ }^{2,3}$
}

ABSTRACT. Reflexivity is arguably an important aspect of doing sustainability research. The inter- and transdisciplinary character of sustainability research, as well as its change-oriented agenda, require scholars to reflect on their role as researchers, their research focus and methodology, and its relation to academia and society. Using focus groups with 15 researchers at different stages in their academic career, we investigate three forms of reflexivity, i.e., personal, functional, and disciplinary, for sustainability researchers connected to the LUCID (Lund University Centre of Excellence for the Integration of the Social and Natural Dimensions of Sustainability) program experience. We further study similarities and differences in how the researchers experience reflexivity connected to interdisciplinary and transdisciplinary approaches. We find that sustainability researchers experience all three forms of reflexivity. In particular, they are highly reflexive about how research on sustainability issues is dependent on theoretical pluralism; how research can contribute to the transformation of society; and how they, as inter- and transdisciplinary researchers, can construct a space for themselves within the academic system. We also find that transdisciplinary approaches make scholars add a layer of reflexivity to the three categories studied, concerning collaboration beyond academia. Finally, we find that reflexivity about these issues seems to be crucial for how sustainability researchers construct a space for themselves within the academic system. PhD graduates from the LUCID program are deeply reflexive about the function of academic boundaries. It is this awareness that enables them to construct an academic identity entirely beyond boundaries. This result has important implications for PhD programs focused toward sustainability issues, in terms of a need to provide opportunities for $\mathrm{PhD}$ students to develop reflexivity.

Key Words: interdisciplinarity; reflexivity; sustainability research; transdisciplinarity

\section{INTRODUCTION}

Efforts to promote and operationalize sustainability research have intensified in recent years. Sustainability is a broad research field, in which the objects of focus are the complex sustainability challenges facing humanity (e.g., climate change, biodiversity loss, human ill-health, poverty) and the myriad interactions among them. Sustainability research challenges scholars to seek a greater understanding of nature-society interactions, with the intention of helping to augment society's ability to guide the interactions along more sustainable pathways (Kates et al. 2001). To fulfill these ambitions, it is argued that the processes of knowledge production for sustainability should be interdisciplinary or even transdisciplinary, making these approaches cornerstones of the field.

The literature (including debates) on interdisciplinarity as a methodology and epistemology is vast. Generally, interdisciplinarity refers to research that cuts across boundaries of academic disciplines or institutions (Castán Broto et al. 2009). More specifically, by interdisciplinary, we mean a process of answering a question, solving a problem, or addressing a topic that is too broad or complex to be dealt with sufficiently by a single discipline, and drawing on multiple disciplines, with the goal of integrating their insight to construct a more comprehensive understanding than would be obtained using a single discipline's viewpoint (Repko et al. 2012). Central to the interdisciplinarity concept is integration, often in the form of knowledge, methods, theories, and disciplines (Lam et al. 2014).

A transdisciplinary approach has also been propounded by many sustainability researchers (Freeman et al. 2015, Roux et al. 2017). In this specific context, much of what transdisciplinary sustainability research entails is captured in a presentation by Jahn et al. (2012): Transdisciplinarity is a critical and self-reflexive research approach that relates societal and scientific problems; it produces new knowledge by integrating different scientific and extrascientific insights; its aim is to contribute to both societal and scientific progress. Integration is the cognitive operation of establishing novel, hitherto nonexistent connections among the distinct epistemic, social-organizational, and communicative entities that make up the given problem context (Jahn et al. 2012).

These transdisciplinary approaches often have the explicit aim of sustainability problem solving within limited spatial (often urban) and temporal parameters. They take place at the interface of societal and scientific problems, discourses, and praxis (Jahn et al. 2012, Lang et al. 2012) and are a meeting place where a common research object, knowledge cocreation, and evaluation and implementation of that knowledge, in both society and academia, take place (Jahn et al. 2012).

Inter- and transdisciplinary research processes, in theory, open opportunities to create more socially robust and salient knowledge on sustainability challenges and solutions that are more relevant for processes of sustainable change. However, the processes are not without their challenges. A few of the many challenges include the added work involved in engaging a team outside of academia for extended periods of time (Steelman et al. 2015, Brink et al. 2018), joint problem defining (Steelman et al. 2015), the hegemony of experts in the projects (Koutsouris 2010), and the ability to draw on a capable body of researchers and practitioners with the abilities to facilitate inter- and transdisciplinary processes.

Research on inter- and transdisciplinarity often concentrates on how they are different from conventional academic disciplinary processes, process design principles or ideals for the research, or analyses of the approach's effectiveness in stimulating sustainable

${ }^{1}$ Department of Political Science, Lund University, ${ }^{2}$ Centre of Excellence for Integration of Social and Natural Dimensions of Sustainability (LUCID), Lund University, ${ }^{3}$ Centre for Sustainability Studies (LUCSUS), Lund University 
social change (Lang et al. 2012, Polk 2014, Scholz and Steiner 2015, Luederitz et al. 2017). Less attention has concentrated on what these approaches mean for the personal development of individual researchers, with a few notable exceptions (e.g., Lyall and Meagher 2012, Felt et al. 2013, Darbellay 2015a, Enright and Facer 2017). As the studies demonstrate, it is difficult to gain a robust understanding of inter- and transdisciplinary approaches, and to further improve them, without having deeper comprehension about how scholars make sense of these processes. Studies of academic and university structures are necessary but insufficient to understand the development of sustainability research and the potential for inter- and transdisciplinary training. Here, we focus on the perceptions of sustainability researchers, rather than on the structural context in which they are situated. It is through the experiences of researchers that the effects of epistemological, institutional, and ideological perspectives connected to inter- or transdisciplinary research can be understood.

Working at the interface of academic disciplines, or at the boundaries between science and society, generates questions about oneself as a researcher. Several studies demonstrate how early career inter- and transdisciplinary researchers "negotiate an identity" (Lyall and Meagher 2012:613) or create "epistemic living spaces" (Felt et al. 2013:514). We argue, as do others (Romm 1998, Lyall and Meagher 2012, Popa et al. 2015, Enright and Facer 2017), that this adaptation necessitates processes of reflexivity whereby researchers continually reconsider their position and role in the research process. In part, we argue that this necessity comes from the concrete nature of the problems that sustainability research seeks to address. Because sustainability researchers often have to explain a complex web of causality, they must develop a capacity for deciding on what bodies of knowledge may be more suitable for addressing concrete sustainability problems and for communicating these choices. Earlier research, however, has not focused on how researchers experience and express reflexivity, with the exception of Enright and Facer (2017). Furthermore, few studies have focused exclusively on sustainability researchers, which are not only expected to work in an inter- or transdisciplinary manner, but also often have an agenda to transform society. This circumstance makes it important to study sustainability scholars, where a focus on researchers' reflexivity can generate important insights into what it means to construct a space in a discipline-nonspecific academic setting, and how that construction influences the identity of researchers immersed in such settings. Furthermore, such an understanding also has implications for how future sustainability researchers are trained.

A concentration on reflexivity implies a study of beliefs and thoughts that researchers have about themselves, their research, and their place in academia and the world. This study deepens and adds nuances to the work of prior studies by specifically focusing on: what sustainability researchers are reflexive about, how reflexivity is perceived by researchers at different academic career stages, and how the duel pressures of performing inter- and transdisciplinary research while attempting to contribute to sustainable societal change influence researchers' reflexivity. To carry out the research, we posed the following questions. (1) What are the main forms of reflexivity experienced by sustainability researchers? (2) What are the similarities and differences in the reflexivity experienced by researchers at different academic career stages? (3) Are there differences in the reflexivity experienced by researchers using interdisciplinary vs. transdisciplinary approaches?

The analysis focuses on the experiences of one sustainability research platform: the 10-year research program LUCID (Lund University Centre of Excellence for the Integration of the Social and Natural Dimensions of Sustainability), based at Lund University, Sweden. It is an interdisciplinary environment, focused on sustainability issues, and with transdisciplinary research ambitions. LUCID includes researchers with backgrounds and affiliations in the natural sciences, social sciences, and humanities. An important part of its endeavors has been a $\mathrm{PhD}$ program, which makes it ideal for studying similarities and differences in reflexivity between researchers at different levels, as well as between those focused on interdisciplinarity and those focused on transdisciplinarity.

LUCID is one of several integrative and novel scientific sustainability and education programs that have been established to meet some of the challenges of inter- and transdisciplinary research processes and promote a new generation of sustainability researchers (Yarime et al. 2012). Other programs are located at Arizona State University, USA; Maastricht University, The Netherlands; Leuphana University of Lüneburg, Germany; University of Tokyo, Japan; and Lund University, Sweden, to name only a few. The programs differ in structure and focus; however, many program curricula consist of a variety of interdisciplinary activities and training in transdisciplinarity help to foster agents for sustainable change.

\section{REFLEXIVITY}

Reflexivity is often viewed as "research that turns back upon and takes account of itself" (Alvesson et al. 2008:480) or "where researchers turn a critical gaze upon themselves" (Finlay 2003:3). Even if most researchers agree on this core description, there is little agreement on a more specific definition (Lynch 2000, Hendriks and Grin 2007). Some scholars choose to use the plural, reflexivities, to indicate its multiple aspects (Finlay 2003, Gough 2003). Several reflexivity typologies have been developed (e.g., Wilkinson 1988, Lynch 2000, Finlay 2003, Alvesson et al. 2008). Most typologies include some form of introspection about how the researcher's personal experiences can be used as an entry point into research or as material in a study. Another important component of reflexivity is the positionality of the researcher, for example, gender, race, and class. Disciplinary belonging can also affect the research, including choice of study object, methods, interpretation, and relation to the study subjects. An additional way to understand reflexivity is in terms of understanding a study's relation to the wider academic field or societal processes.

Some typologies highlight the collaborative aspects of reflexivity whereby research is seen as a process that is shared among several researchers or research participants (Finlay 2003, Alvesson et al. 2008). This form is often highlighted in transdisciplinary approaches. Exemplifying the collaborative components are Popa et al. (2015:47), where they highlight "a collaborative process of acknowledgement, critical deliberation and mutual learning on values, assumptions and understandings that enables the generation of 'new meanings, new heuristics, and new stakeholder identities" (quotation within attributed to Lenoble and Maesschalck 2010). 
To keep the typology simple yet precise, we use the one by Wilkinson (1988) because it delineates only three forms of reflexivity: personal, functional, and disciplinary. Personal reflexivity highlights a process of how personal interests, values, and life experiences influence the choice of what to study, and how research feeds back into those interests and values, creating new life experiences. Functional reflexivity concentrates on the role of researchers and how it is affected by the researchers' positionality. Furthermore, it considers how researchers approach research subjects. Finally, disciplinary reflexivity entails being reflexive about a researcher's relation to different academic paradigms, including norms within particular disciplines, and more general academic ideals. According to Wilkinson (1988), the first two categories are intertwined and difficult to separate. The typology, therefore, does not make a distinction between personal experience and positionality, as do many other typologies, but rather between the researcher as person and as researcher.

\section{METHODS}

We used focus groups to study researchers' reflexivity because, through its inherent group dynamic, it is a method suitable for uncovering deeper beliefs and thoughts (Stewart et al. 2007). Benefits of focus group interviews include that they provide possibilities for clarification, follow-up questions, and probing, as well as for studying deeper levels of meaning, connections, and nuances. Group dynamics are crucial as they allow individuals to react to ideas from others in the group. This interaction can uncover issues that would not be apparent in individual interviews, and disagreements in the group can help the researcher to identify reasons for the support or rejection of particular ideas.

\section{Research process}

We sent out an invitation to researchers connected to LUCID to participate in the focus groups, together with information about the project and three open-ended questions for discussion, accompanied by a short text that presented a broad understanding of reflexivity (Appendix 1). In doing so, we did not wish to delimit the discussions, but rather tap into what the researchers understood as reflexivity. At the same time, participants needed some idea of what we were interested in studying. During the sessions, we employed a hands-off approach, with intention of enabling broader discussions of reflexivity. The focus groups included ten researchers: two PhD student groups with four participants in each group, and one professor group with two participants. We aggregated the responses from the PhD groups and treated them as one group. This division was made to enable a comparison of researchers at different career stages and to ensure adequate contribution from all participants. However, there were no researchers with a recent $\mathrm{PhD}$ degree, so to include this group, we sent out a second invitation to individuals at this level for a later focus group interview. This resulted in an additional group with five participants (one participated via video conferencing). In total, the focus groups comprised 15 researchers. The sessions were approximately $1.5 \mathrm{~h}$, recorded, and later transcribed.

The analysis was conducted in four steps. First, the discussions were coded according to category of reflexivity. Second, within each category, the coded statements were divided into themes. The themes were derived inductively from the discussions. This enabled us to see what researchers were focusing on within each category. The themes were rather similar across the focus groups and included, for example, motivation (personal reflexivity), relation between the research and research subject (functional reflexivity), and disciplinarity or interdisciplinarity (disciplinary reflexivity). To enable stringency in the analysis, the categorization and thematization of statements were discussed within the research team. Third, we analyzed the statements to find similarities and differences between the researchers at different career stages. Finally, the statements were analyzed to discover the similarities and differences between reflexivity associated with interdisciplinary vs. transdisciplinary approaches. Beyond the comparison of different career groups, we also considered individual differences, to be able to capture, for example, the influence of the participants' affiliations. The main findings are presented by group, and we use quotations from participants throughout to emphasize the main points.

\section{RESULTS}

All three categories of reflexivity (i.e., personal, functional, disciplinary) were discussed in all focus groups (Fig. 1). The number of coded statements related to reflexivity was 171 from the $\mathrm{PhD}$ students groups (100 from group 1, 71 from group 2), 110 from the PhD graduate group, and 53 from the professor group.

Fig. 1. Percentage of researcher statements concerning each type of reflexivity for three career stages.

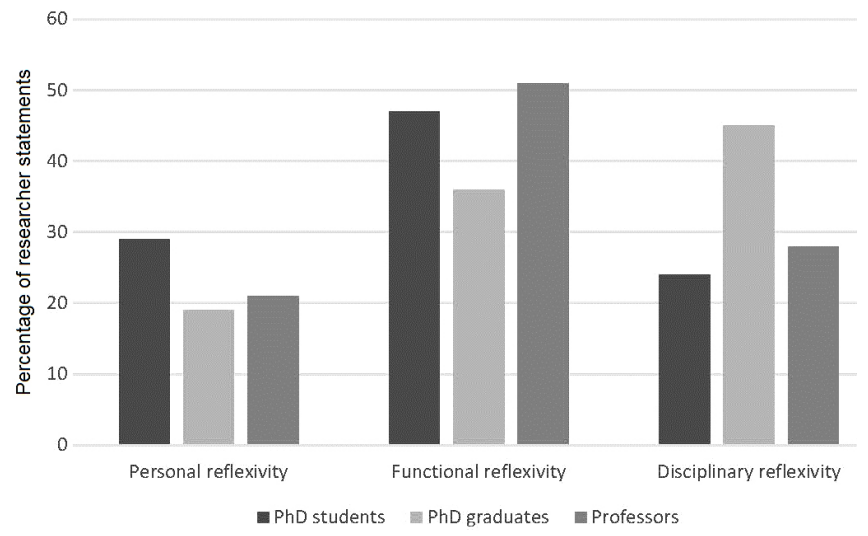

Combined, more weight was given to functional reflexivity, in terms of number of statements and time spent discussing. It was only in the $\mathrm{PhD}$ graduate group that this category was less important. Instead, more focus was placed on disciplinary reflexivity. The $\mathrm{PhD}$ students spent more time on personal reflexivity, compared to the $\mathrm{PhD}$ graduates and professors.

\section{PhD student group}

The PhD students had a more diverse disciplinary background than the other groups. All but one participant were $\mathrm{PhD}$ students within a discipline but also with a connection to LUCID. Only one was $\mathrm{PhD}$ student in sustainability science. Concerning personal reflexivity, the $\mathrm{PhD}$ students discussed their positionality, for example, their origin and what it means for their research. They also expressed feelings connected to research. 
Their motivation for doing sustainability research was mostly personal, for example, finding it interesting, but also emphasizing that their research contributes to societal change.

\section{[...] people choose such irrelevant things to study. Imean they are not irrelevant, like they can be interesting, but they are so far beside the point so it's a bit of a waste... [...] But I mean it's almost like you don't really want to look at the problem.}

They discussed functional reflexivity extensively. Participants pondered on how bringing about change was part of their role as researchers and how they could achieve it without imposing their views on others.

I interact with kind of specific, strategically chosen organizations that I think have potential to do... something and who has the legitimacy of doing things that I don't have as an external person. Where in our interaction I can somehow contribute, not by dictating, but by having a dialogue with them. And, you know, somehow, strengthening what they do. Because I see that it is sometimes quite useful to have a kind of outsider's perspective beyond what you are doing. I feel that that could be the case for me, and I think be the case for them, so I can be that kind of agent.

The group discussed how research can be conducted and what reflexivity is about. Some expressed an insecurity about what reflexivity entailed. They also discussed in some length how the methodological choices made affect the study, as well as what influence encountering the field has on your research.

$\mathrm{PhD}$ students discussed disciplinary reflexivity, but to a lesser extent than the other areas. One aspect that they discussed was how to position oneself in relation to disciplines and interdisciplinarity. Another aspect that came up was about differences between natural scientific and interdisciplinary research. Some of the $\mathrm{PhD}$ students also highlighted how interdisciplinary research forces the researcher to be reflexive.

\section{PhD graduate group}

The participants in the $\mathrm{PhD}$ graduate group had very mixed disciplinary backgrounds, but all had recently received a degree in sustainability science. The discussion significantly differed from the discussions of the $\mathrm{PhD}$ students. Concerning personal reflexivity, they only brought up their positionality or their personal feelings to a very limited degree. Instead, they discussed their motivation for doing sustainability research as both being personally motivated and change oriented. Several of the participants highlighted that it is important to be personally motivated or grounded in the research. They showed less uncertainty about reflexivity. Several of them saw reflexivity in research as no different from reflexivity in life.

I can't differ between my reflexivity as a researcher from... me as a person. Imean, that's the same as deciding every day if you do the right thing or how you handle situations, what kind of tone you have in a discussion... [...] I don't think it is a specific type of reflexivity that we do in research compared to being a practitioner, for instance. It's the same choices: Am I working with the right approaches here? Have we formulated the problem in the right way? Is this solution really good? I mean, it is the same.

As in the other groups, a lot of time was spent discussing functional reflexivity. They all saw reflexivity as a central aspect of being a researcher. They did not express insecurity about their research, but several of them commented on how they act as experts, or when the role of an expert was forced upon them.

I have been in situations where basically "you are from the university, you are an assistant professor, you have a $P h D$, you have to know. " And I'm like, ok. I can't really say that I don't know, because you know...

* group laughs*

$[\ldots]$

... and then basically "here, have the last word and say something." And if you don't say something... then why are you even here. So you have to say something that is based on the best evidence that you have. [...] And yes, I think you are an expert. We are experts. We do not necessarily think of ourselves as experts... [...] And I think this is [...] because we are reflexive... [...] If you're truly reflexive and if you're truly are thinking about ourselves and our roles you would never claim that you are an expert.

Another aspect of insecurity was how they could interact with radically different ways of understanding when encountering people in the field. The three participants that discussed this, agreed that changing the power relation between researcher and research subjects could be a way of handling it, for example, by allowing research subjects to influence the problem formulation or the general direction of the study. The other two participants were more inclined to conduct research with a more traditional power balance.

Most time in the $\mathrm{PhD}$ graduate group was spent on disciplinary reflexivity. The difference, in comparison to the other groups, was not only the time spent on the subject, but also what was discussed. The discussion was on a higher level of abstraction than in the $\mathrm{PhD}$ student group. It was less about how they maneuvered in the academic system, and more about the academic system, as such. They discussed the similarities and differences between disciplinary and interdisciplinary research, mostly similarities. However, instead of focusing on the disciplinary belonging of other researchers, they focused on the subject of their research. In addition, quite some time was devoted to discussion about how disciplinary boundaries are detrimental to good research. This perspective was particularly advocated by one participant. Compared to participants in the other groups, they were also more critical toward interdisciplinary research, sustainability science, and LUCID, seeing the limitations of these paradigms and structures. All of them discussed their research competence and its fit into the broader academic context. Several of them described themselves as generalists, bringing together different perspectives or understandings.

I think you don't have to be an expert on different things. I think it's good enough that you know who is the expert, and you can work with them and understand the basics. And you then are the expert in kind of keeping an 
umbrella. And I think that actually is needed. I mean honestly, and you can see the changes in society and like in jobs where people are actually demanding a bit of a broader perspective.

One of them also brought up an ability to change perspective depending on what was missing in a project team.

I ask different questions than other people, but I also realize that the type of questions I ask depend on whom I work with. Because if there is a natural scientist then I ask the social science question. If I'm working with a social scientist, then I tend to ask the natural science question or the economics question. So, I take on different roles based on whom I'm working with, because in my mind I'm thinking about what is the dynamic that we get to be able to see things from different perspectives.

At the same time as they see themselves transcending boundaries, they are very aware of the necessity to adapt to these boundaries to get funding, work positions, and publications.

The experience that I am making right now with writing one grant application after the other while being unemployed and writing job applications [...] I feel you have to accommodate a lot to the funding organization. You have to accommodate, you have to adapt your language. When I applied for a job at [a department at Lund University] [...], that made me [...] change my language and adapt language that I would otherwise not like that much. [...] Whereas publications I think it's easier because then you just go to a different journal in the end...

\section{Professor group}

Consisting of two participants, the professor group resulted in comparatively fewer statements. They had very different disciplinary backgrounds with disciplinary degrees from two different fields. Both were Swedish speakers, and the discussion was held in Swedish. They focused to a relatively low extent on personal reflexivity; mostly one of the participants talked about this. Focus was placed on motivation, foremost change oriented.

In this group, most of the time was spent on functional reflexivity. Both participants talked about research projects and how these had influenced their way of thinking about research. One of the participants talked about the role of the researcher as being a mediator between theories and observations in the field, but also between different research subjects. The other participant focused more on the relation between researcher and research subjects and the difficulties of achieving transformation without imposing one's views on others. Both participants discussed how the power relation between researcher and research subject can be changed.

One of the participants in this group concentrated on disciplinary reflexivity to quite an extent. This participant defined his/her identity as an interdisciplinary researcher in relation to natural science and his/her former disciplinary home. This researcher saw reflexivity as crucial for interdisciplinary research but not present in disciplinary natural science. Both participants discussed the necessity of theoretical pluralism for interdisciplinary research.

\section{DISCUSSION}

The results support the general insight by Cuevas-Garcia (2015:86) that "claiming an interdisciplinary self and identity is not a straightforward task." The researchers have a high awareness of the need for reflexive processes in sustainability research, including the three types of reflexivity studied here. The focus group discussions also revealed more targeted insights into how they develop their reflexivity and how it relates to inter- and transdisciplinary sustainability research, as well as how these insights can be harnessed to improve education in this field.

Reflexivity in inter- and transdisciplinary sustainability research The researchers in all groups expressed reflexivity that is connected either to the character of sustainability research or to its inter- and transdisciplinary aspects. First, the researchers viewed the use of several different theoretical perspectives as imperative to understanding the complexity of the problems studied. Second, the researchers were deeply reflexive about how their research connected to society and actors outside of academia. Finally, all researchers focused to a relatively high extent on disciplinary reflexivity.

Researchers in all groups discussed the importance, even the necessity, of using several theoretical perspectives to understand better the complex nature of the problems they study. This broadening of perspectives could be done either by building interdisciplinary teams or by an individual researcher being open to multiple theoretical perspectives. The researchers took the studied problem as point of departure for what perspectives and tools to use. Romm (1998) argues that the major difference between multidisciplinary and interdisciplinary perspectives is interdisciplinary researchers' willingness to reexamine their initial positions and shift perspectives. This viewpoint is apparent in our study. Theoretical pluralism as such also deepens the researchers' reflexivity because they become aware of the limits to the understanding of complex problems. This perspective led several to comment on the need to be humble as researcher.

Almost all researchers discussed their motives for doing research as oriented toward society. For many, the wish to change the world in a more sustainable direction was the main driver of the research they performed. They also highlighted the wish for societal change in their role as researcher and in the relation to research subjects, for example, by focusing on the role of research subjects to change unsustainable practices. In a study of 24 early career researchers, Enright and Facer (2017) showed that most of the researchers wanted to affect society, whereas only a small number saw their research as a tool to do so. In our study, most participants expressed a general wish to change society, and many of them actually adapted their research strategies to enable that. This difference between the PhD students in Enright and Facer's (2017) study, participating in a broad PhD program, and our researchers with their focus on sustainability issues, could be traced to the transformative agenda of sustainability research. The orientation toward society was foremost expressed as personal or functional reflexivity.

All researchers discussed disciplinary reflexivity. According to Wilkinson (1988), disciplinary reflexivity is a deep form of reflexivity, and therefore, more unusual. It is not surprising, however, that inter- and transdisciplinary researchers display 
reflexivity about their place in the academic system and how they relate to different disciplinary and interdisciplinary norms. This reflexivity can be connected to the need to find "epistemic living spaces" (Felt et al. 2013:514) in between or beyond disciplines. Research has shown that almost all strategies that inter- and transdisciplinary researchers use include relating themselves to existing disciplines (Darbellay 2015b, Enright and Facer 2017), at least in terms of publishing and getting funding (Lau and Pasquini 2008). However, our study shows that researchers can understand these issues very differently.

Our results show that the sustainability researchers in our study are reflexive about aspects that are connected to the double duties of doing inter- and transdisciplinarity research and transforming society. The importance they place on including several theoretical perspectives in their studies is connected to interdisciplinary research, but even more to the complexity of sustainability problems. The importance of reflexivity connected to the orientation toward society can be directly connected to the transformational aspirations of sustainability research. Finally, the focus on disciplinary reflexivity is more dependent on the interdisciplinary character of their research.

\section{How sustainability researchers construct an academic space for themselves}

The results show that what scholars are reflexive about differs depending on the career stage of the researcher. The differences reflect aspects likely present in the development of most research identities, but also aspects that are connected to the area of sustainability research. The more general aspects of change include PhD students being more uncertain about their identity and their role as researchers, whereas $\mathrm{PhD}$ graduates and professors are more certain of their academic identity. For the $\mathrm{PhD}$ graduates, new areas of uncertainty were how to relate to the expert role and to the need to get funding and positions.

The major difference between researchers at the three career stages was how the researchers expressed disciplinary reflexivity. The discussion in the PhD graduate group stood out from the other discussions. The $\mathrm{PhD}$ graduates discussed how their competencies as sustainability researchers were based on them being generalists, with an ability to bring together research teams, enable discussion over disciplinary boundaries, and see what perspectives were missing in a project. They also situated their competencies in the wider university system and academic research at large. These qualities are connected to a deeper understanding of epistemological issues, but also of how boundaries work in the academic system. The PhD graduates had developed a deep understanding of what boundaries implied for them as well as for the academic system. They discussed disciplinary boundaries as a problem in terms of getting funding, but also as a general problem for the university system. In particular, one researcher focused on the limiting effects these boundaries have for research and advocated that they be discarded. Several of the others could see some benefits with the boundaries or could at least accept them. Further, they criticized sustainability research for being limiting and not fulfilling its interdisciplinary and reflexive potential.

For the researchers in the $\mathrm{PhD}$ graduates group, disciplinary boundaries seem to be unimportant for how they understand themselves as researchers. Even if they are very sensitive to what effect boundaries have, they have constructed their academic identity and academic space as beyond disciplinary boundaries. However, they relate themselves to the new field of sustainability science not uncritically. They focus not on disciplinary belongings of researchers, but on their thematic focus and if it fits with their own focus. As such, they can be categorized as "a thematic profile type," according to Darbellay (2015b:204). They let their focus decide what direction they take as researchers, without consideration of disciplines. This difference compared to the professor group is stark. One of the two professors can, with Darbellay's vocabulary (2015b:205), be categorized as a "migrant" researcher, who has a disciplinary background but has become increasingly interdisciplinary. The other professor discussed disciplinary reflexivity only to a limited extent and is therefore difficult to categorize. The "migrant" professor clearly understood interdisciplinarity in relation to disciplinary research and norms (see also Castán Broto et al. 2009). The PhD students in our study also positioned themselves in relation to disciplines. There was no difference between the $\mathrm{PhD}$ student in sustainability science and the disciplinary $\mathrm{PhD}$ students in how they discussed positioning themselves in relation to disciplines. Even while recognizing that disciplines are important reference points for them, they understood themselves as beyond disciplines.

Interviewer: What about the larger research traditions?
We have one [participant] from human ecology, physical
geography, sociology, and sustainability science. What is
reflexiv[ity] about as being a researcher within these
different research traditions?

Participant 1: I'm not a sociologist.

*group laughs*

Participant 2: And I'm not a geographer.

Participant 3: And I'm not a human ecologist.

*group laughs*

Participant 2: I guess that says it all.

Participant 4: Yeah, it's a new generation.

They further emphasized the positive aspects of interdisciplinary environments and projects, especially the importance that it played for them in being reflexive.

Our study demonstrates that the PhD graduates, who have been trained as inter- or transdisciplinary sustainability researchers, have developed a reflexive capacity that enables them to evaluate constantly how academic boundaries affect their possibilities to do sustainability research, but without letting those boundaries define who they are as researchers. The awareness of boundaries seems to enable them to go beyond them. Other studies often make a distinction between researchers that relate to boundaries and those that are beyond them (e.g., Darbellay 2015b, Enright and Facer 2017). Our study indicates that the ability to be reflexive over the interrelation between boundaries and boundlessness is what defines them, demonstrating that these scholars have formed a new generation with the capacity not just to create an academic space for themselves, but the understanding and enthusiasm to change academic structures from within. 
As all the $\mathrm{PhD}$ graduates in our study held a $\mathrm{PhD}$ in sustainability science, it is impossible to draw conclusions about how the double affiliation of many of the $\mathrm{PhD}$ students will affect their reflexivity as they proceed in their academic careers. One possibility is that the double affiliation will make them even more sensitive to academic boundaries and increase their ability to navigate them. However, more studies are needed on this issue, especially comparing how sustainability researchers that are trained in different types of academic contexts develop reflexivity, and how that reflexivity enables them to construct an academic space for themselves.

\section{Differences between inter- and transdisciplinary reflexivity}

Our study shows that transdisciplinary reflexivity is not a separate form of reflexivity, as the collaborative category of reflexivity suggested by some (e.g., Alvesson et al. 2008) can indicate. Instead, we must understand transdisciplinary reflexivity as an additional layer in personal, functional, and disciplinary reflexivity. Three of the $\mathrm{PhD}$ students and one of the $\mathrm{PhD}$ graduates consistently discussed research in a different way than the others did, expressing aspects of transdisciplinarity in relation to all three reflexivity types. This perspective included a wish to do research that people think is important.

\section{I don't want to make up a problem, but rather to talk to the people: What are you dealing with? What could I contribute with?}

Thus, they went beyond the other researchers' wish to change society to letting nonacademics define what the problems are. To realize this outcome, these researchers changed the way they worked to enable more active participation of people in their research projects, including participation in problem definition and giving feedback on interpretations. In this sense, they understood research as a tool for transforming society.

None of the PhD students discussed transdisciplinary aspects in terms of disciplinary reflexivity. The $\mathrm{PhD}$ graduate that did so did it on a rather high level of abstraction, questioning boundaries between academic and lay knowledge. We find the fact that none of them discussed transdisciplinarity in relation to the established norms of doing research surprising. They did not feel the need, within the focus groups, to defend transdisciplinary research strategies or relate them to more traditional research forms. This indicates that among the sustainability researchers, transdisciplinarity is an accepted way of working, although not all participants in our study adopted it.

The difference between inter- and transdisciplinary reflexivity among the researchers can be seen as an additional layer of reflexivity concerning collaborative aspects. Among the interdisciplinary oriented researchers, many highlighted the importance of collaboration with other academics. However, the more transdisciplinary oriented ones focus on collaboration beyond academia. Even if most of the researchers in our study want to change society, they do not use extra-academic collaboration in research as a tool for doing so.

\section{Implications for sustainability education}

It is not self-evident what implications the above insights should generate for sustainability education and research. One conclusion is that the education of sustainability $\mathrm{PhD}$ students should focus on developing their reflexive capacity because it is an important competence for doing research beyond borders. However, it is unclear how this development should be done. Several studies propose to introduce the students to workshop activities or other forms of encounters where they can engage with a diverse range of academics (Lyall and Meagher 2012, Bridle et al. 2013). This process would create circumstances where they are "pushed out of their comfort zone," as one of the $\mathrm{PhD}$ students put it. However, if a $\mathrm{PhD}$ student is connected to an inter- or transdisciplinary environment, these encounters will happen without deliberately including them in the $\mathrm{PhD}$ program, not least through the interaction with fellow PhD students, both inside and outside of academia. If the environment does not offer the opportunity to meet researchers with a wide variety of perspectives and using different theories and methods, creating such encounters in the $\mathrm{PhD}$ program will generate circumstances were $\mathrm{PhD}$ students can develop their reflexivity. Such encounters also create networks, which can be used for building research teams later in their careers. Thus, it is important to consider the affiliation that $\mathrm{PhD}$ students have and what possible effects it has on their reflexivity. However, to teach or tutor $\mathrm{PhD}$ students to become more reflexive can prove difficult, as the $\mathrm{PhD}$ graduates concluded in a discussion about whether disagreements over ontology and epistemology could create reflexivity or if a reflexive capacity is a prerequisite to make such disagreements meaningful.

\section{Participant 1: If I go back to who I was, I don't know if I could have a meaningful discussion about it because I didn't know much about it...}

*Several particpants agree*

Participant 1:... so now we could have a more meaningful discussion, because we know... we have our experience and we've been working on this for a while. But back then... It's like the chicken and the egg...

Reflexivity is not something that can be taught; a reflexive capacity has to build on experiences. Supervisors and program organizers can create a variety of opportunities in which reflexivity can be developed, yet cannot guide $\mathrm{PhD}$ students directly to a reflexive capacity.

\section{CONCLUSION}

The aim of this research was to study three forms of reflexivity among sustainability researchers. Our study of 15 scholars at different stages in their academic careers, connected to the research platform LUCID, indicates that these sustainability researchers' reflexivity is highly connected to the inter- and transdisciplinary character of sustainability research, as well as to its transformational agenda. Their way of managing the complexity of sustainability issues is to adopt theoretical pluralism, which also strengthens their reflexivity. Further, they have a society-oriented approach, making them acutely aware of connections between research and society. They also consider how they and their research fits into the wider academic system. Furthermore, our study points to the effect of inter- and transdisciplinary $\mathrm{PhD}$ training for reflexivity development. The $\mathrm{PhD}$ graduates, who all held degrees in sustainability science, are highly aware of academic boundaries, yet do not define themselves as researchers in relation to them. Their understanding of the interplay between boundaries and boundlessness seem to 
be defining them as researchers. This was not the case among either the PhD students, who had not yet developed such a sensitivity, or the professors, who had received disciplinary training. There are differences in terms of reflexivity between inter- and transdisciplinarity oriented scholars in our study, but not in terms of category of reflexivity. Rather, the difference can be seen as an additional layer of reflexivity in all categories, focused on extra-academic collaboration. The implications of this viewpoint for the education of sustainability researchers are not quite clear, and more research is needed on how different research environments affect the development of $\mathrm{PhD}$ students' reflexivity and how researchers subsequently create an academic space for themselves within or beyond academic boundaries. What can be emphasized from our study is that $\mathrm{PhD}$ students need to meet diverse perspectives and that $\mathrm{PhD}$ programs need to encourage and enable this process.

Responses to this article can be read online at: http://www.ecologyandsociety.org/issues/responses. php/10505

\section{Acknowledgments:}

We thank the Lund University Centre of Excellence for the Integration of the Social and Natural Dimensions of Sustainability (LUCID) for supporting this research. Furthermore, we thank Stephen Woroniecki for contributions to the early project work that led to this paper, and the anonymous reviewers who have helped us to improve the subsequent versions of this paper.

\section{LITERATURE CITED}

Alvesson, M., C. Hardy, and B. Harley. 2008. Reflecting on reflexivity: Reflexive textual practices in organization and management theory. Journal of Management Studies 45 (3):480-501. http://dx.doi.org/10.1111/j.1467-6486.2007.00765.x

Bridle, H., A. Vrieling, M. Cardillo, Y. Araya, and L. Hinojosa. 2013. Preparing for an interdisciplinary future: a perspective from early-career researchers. Futures 53:22-32. http://dx.doi. org/10.1016/j.futures.2013.09.003

Brink, E., C. Wamsler, M. Adolfsson, M. Axelsson, T. Beery, H. Björn, T. Bramryd, N. Ekelund, T. Jephson, W. Narvelo, B. Ness, K. I. Jönsson, T. Palo, M. Sjeldrup, S. Stålhammar, and G. Thiere. 2018. On the road to 'research municipalities': analysing transdisciplinarity in municipal ecosystem services and adaptation planning. Sustainability Science 13(3):765-784. doi:10.1007/s11625-017-0499-0 http://dx.doi.org/10.1007/ s11625-017-0499-0

Castán Broto, V., M. Gislason, and M.-H. Ehlers. 2009. Practising interdisciplinarity in the interplay between disciplines: experiences of established researchers. Environmental Science and Policy 12(7):922-933. http://dx.doi.org/10.1016/j.envsci.2009.04.005

Cuevas-Garcia, C. A. 2015. 'I have never cared for particular disciplines' - negotiating an interdisciplinary self in biographical narrative. Contemporary Social Science 10(1):86-98. http://dx.doi. org/10.1080/21582041.2014.974664
Darbellay, F. 2015a. Rethinking inter- and transdisciplinarity: undisciplined knowledge and the emergence of a new thought style. Futures 65:163-174. https://doi.org/10.1016/j.futures.2014.10.009

Darbellay, F. 2015b. The gift of interdisciplinarity: towards an ability to think across disciplines. International Journal for Talent Development and Creativity 3(2):201-211.

Enright, B., and K. Facer. 2017. Developing reflexive identities through collaborative, interdisciplinary and precarious work: the experience of early career researchers. Globalisation, Societies and Education 15(5):621-634. http://dx.doi.org/10.1080/14767724.20$\underline{16.1199319}$

Felt, U., J. Igelsböck, A. Schikowitz, and T. Völker. 2013. Growing into what? The (un-)disciplined socialisation of early stage researchers in transdisciplinary research. Higher Education 65 (4):511-524. http://dx.doi.org/10.1007/s10734-012-9560-1

Finlay, L. 2003. The reflexive journey: mapping multiple routes. Pages 3-20 in L. Finlay and B. Gough, editors. Reflexivity: a practical guide for researchers in health and social sciences. Blackwell, Oxford, UK. http://dx.doi.org/10.1002/9780470776094. ch1

Freeman, O. E., L. A. Duguma, and P. A. Minang. 2015. Operationalizing the integrated landscape approach in practice. Ecology and Society 20(1):24. http://dx.doi.org/10.5751/ ES-07175-200124

Gough, B. 2003. Deconstructing reflexivity. Pages 21-35 in L. Finlay and B. Gough, editors. Reflexivity: a practical guide for researchers in health and social sciences. Blackwell, Oxford, UK. https://doi.org/10.1002/9780470776094.ch2

Hendriks, C. M., and J. Grin. 2007. Contextualizing reflexive governance: the politics of Dutch transitions to sustainability. Journal of Environmental Policy and Planning 9(3-4):333-350. http://dx.doi.org/10.1080/15239080701622790

Jahn, T., M. Bergmann, and F. Keil. 2012. Transdisciplinarity: between mainstreaming and marginalization. Ecological Economics 79:1-10. http://dx.doi.org/10.1016/j.ecolecon.2012.04.017

Kates, R. W., W. C. Clark, R. Corell, J. M. Hall, C. C. Jaeger, I. Lowe, J. J. McCarthy, H. J. Schellnhuber, B. Bolin, N. M. Dickson, S. Faucheux, G. C. Gallopin, A. Grübler, B. Huntley, J. Jäger, N. S. Jodha, R. E. Kasperson, A. Mabogunje, P. Matson, H. Mooney, B. Moore III, T. O'Riordan, and U. Svedin. 2001. Sustainability science. Science 292(5517), 641-642. http://dx.doi.org/10.1126/ science. 1059386

Koutsouris, A. 2010. Transdisciplinarity and participatory development: a critical realist approach. International Journal of Interdisciplinary Social Sciences: Annual Review 5(4):253-264. https://doi.org/10.18848/1833-1882/CGP/v05i04/51689

Lam, J. C. K., R. M. Walker, and P. Hills. 2014. Interdisciplinarity in sustainability studies: a review. Sustainable Development 22 (3):158-176. http://dx.doi.org/10.1002/sd.533

Lang, D. J., A. Wiek, M. Bergmann, M. Stauffacher, P. Martens, P. Moll, M. Swilling, and C. J. Thomas. 2012. Transdisciplinary research in sustainability science: practice, principles, and challenges. Sustainability Science 7(S1):25-43. http://dx.doi. org/10.1007/s11625-011-0149-x 
Lau, L., and M. Pasquini. 2008. 'Jack of all trades'? The negotiation of interdisciplinarity within geography. Geoforum 39 (2):552-560. http://dx.doi.org/10.1016/j.geoforum.2006.08.013

Lenoble, J., and M. Maesschalck. 2010. Democracy, law and governance. Ashgate, Farnham, UK. http://dx.doi. org/10.4324/9781315576435

Luederitz, C., N. Schäpke, A. Wiek, D. J. Lang, M. Bergmann, J. J. Bos, S. Burch, A. Davies, J. Evans, A. König, M. A. Farrelly, N. Forrest, N. Frantzeskaki, R. B. Gibson, B. Kay, D. Loorbach, K. McCormick, O. Parodi, F. Rauschmayer, U. Schneidewind, M. Stauffacher, F. Stelzer, G. Trencher, J. Venjakob, P. J. Vergragt, H. von Wehrden, and F. R. Westley. 2017. Learning through evaluation - a tentaitive evaluation scheme for sustainability transtions experiments. Journal of Cleaner Production 169:61-76. http://dx.doi.org/10.1016/j.jclepro.2016.09.005

Lyall, C., and L. R. Meagher. 2012. A masterclass in interdisciplinarity: research into practice in training the next generation of interdisciplinary researchers. Futures 44 (6):608-617. http://dx.doi.org/10.1016/j.futures.2012.03.011

Lynch, M. 2000. Against reflexivity as an academic virtue and source of privileged knowledge. Theory, Culture and Society 17 (3):26-54. http://dx.doi.org/10.1177/02632760022051202

Polk, M. 2014. Achieving the promise of transdisciplinarity: a critical exploration of the relationship between transdisciplinary research and societal problem solving. Sustainability Science 9 (4):439-451. http://dx.doi.org/10.1007/s11625-014-0247-7

Popa, F., M. Guillermin, and T. Dedeurwaerdere. 2015. A pragmatist approach to transdisciplinarity in sustainability research: from complex systems theory to reflexive science. Futures 65:45-56. http://dx.doi.org/10.1016/j.futures.2014.02.002

Repko, A. F., W. H. Newell, and R. Szostak. 2012. Case studies in interdisciplinary research. Sage, Thousand Oaks, California, USA. http://dx.doi.org/10.4135/9781483349541

Romm, N. R. A. 1998. Interdisciplinary practice as reflexivity. Systemic Practice and Action Research 11(1):63-77. https://doi. org/10.1023/A:1022964905762

Roux, D. J., J. L. Nel, G. Cundill, P. O'Farrell, and C. Fabricius. 2017. Transdisciplinary research for systemic change: who to learn with, what to learn about and how to learn. Sustainability Science 12(5):711-726. http://dx.doi.org/10.1007/s11625-017-0446-0

Scholz, R. W., and G. Steiner. 2015. The real type and ideal type of transdisciplinary processes: part I-theoretical foundations. Sustainability Science 10(4):527-544. http://dx.doi.org/10.1007/ s11625-015-0326-4

Steelman, T., E. G. Nichols, A. James, L. Bradford, L. Ebersöhn, V. Scherman, F. Omidire, D. N. Bunn, W. Twine, and M. R. McHale. 2015. Practicing the science of sustainability: the challenges of transdisciplinarity in a developing world context. Sustainability Science 10(4):581-599. https://doi.org/10.1007/ s11625-015-0334-4

Stewart, D. W., P. N. Shamdasani, and D. W. Rook. 2007. Focus groups: theory and practice. Second edition. Sage, Thousand Oaks, California, USA.
Wilkinson, S. 1988. The role of reflexivity in feminist psychology. Women's Studies International Forum 11(5):493-502. http://dx. doi.org/10.1016/0277-5395(88)90024-6

Yarime, M., G. Trencher, T. Mino, R. W. Scholz, L. Olsson, B. Ness, N. Frantzeskaki, and J. Rotmans. 2012. Establishing sustainability science in higher education institutions: towards an integration of academic development, institutionalization, and stakeholder collaborations. Sustainability Science 7(S1):101-113. http://dx.doi.org/10.1007/s11625-012-0157-5 


\section{Appendix}

\section{LUCID focus group discussions on reflexivity}

Thursday 23 March, 10.15-12

As you are aware, we are studying reflexivity in sustainability research. The core of reflexivity is often seen as "research that turns back upon and takes account of itself" (Alvesson et al 2008). As we have discussed, reflexivity is a broad concept with different definitions. Therefore, we are interested in the different "types" of reflexivity that researchers find important and how they translate that into research practice (i.e. methods and research design). Below you will find a short text that discusses different understandings of reflexivity.

Based on the above, we would like to invite you to focus group discussions on the topic. The focus groups will constitute an important part of our material for this study and we hope that you will be interested in actively participating. Participants will be divided into groups following research seniority. The discussions will be recorded.

In preparation of the session, we ask you to read the short introduction to reflexivity included in this mail and reflect over the questions below (further preparation is not necessary):

- What are you reflexive about as researcher? Specifically, are there examples in your role as researcher vis-à-vis the object of study / research subjects or participants / interpretation / larger research tradition / changing the world

- How do you translate reflexivity about these issues into practice in your research?

- What are your motivations for being reflexive when carrying out research? Is it necessary (or not) and if so why?

We appreciate your participation and look forward to the discussions!

Barry, David, Stephen, Åsa 
Reflexivity in research is often seen as "research that turns back upon and takes account of itself" (Alvesson et al 2008), or "where researchers turn a critical gaze upon themselves" (Finlay 2008). Even if most researchers agree on this type of core definition, there is no agreement on a more specific definition. Rather, many chose to use the plural reflexivities, to indicate that it can consist of many different things (Finlay 2008; Gough 2008). Many different typologies exist (e.g. Finlay 2008; Alvesson et al 2008; Lynch 2000; Wilkinson 1988). Most of these typologies include some form of "personal" reflexivity (Wilkinson 1988), or introspection (Finlay 2008). This implies that the reflexive gaze is turned towards how the researcher's own experiences can be used as either entry point to research or as material in a study. Another aspect of reflexivity is how the situatedness of the researcher, for example in terms of gender, race and class, but also disciplinary belonging, impacts on the research, including choice of study object, methods, interpretation, and relations to the study subjects (MacBeth 2001; Wilkinson 1988). Some of the typologies include reflexivity as collaboration, were research is seen as a processes that is shared among several researchers, but also with other participants (Alvesson et al 2008; Finlay 2008). A further way to understand reflexivity is in terms of understanding a study's relation to the wider academic field or societal processes (Alvesson et al 2008; Wilkinson 1988). Often the authority of the researcher is held forth as problematic and an effort is made to enable multiple voices to be heard. Another type of reflexivity that is often listed concerns the text and how it is both contestable and constructive. A further aspect of reflexivity is discussed by Kuehner et al (2016). They differentiate between weak and strong reflexivity, where the aim of the first is to use reflexivity to decrease the influence of researcher and context on the study, whereas the situatedness and experience of the researcher in the second is seen as strength.

Given this, the meaning of reflexivity is highly context dependent and varies with the interest and focus of the authors. In the context of sustainability research, we believe that specific types of reflexivity are important, that might be less so in studies with other focus. There might also be important differences in terms of the study object as well as the theoretical perspective used. We wish to explore these types of reflexivities.

\section{References}

Alvesson, M, Hardey, C, Harley, B (2008). "Reflecting on reflexivity: Reflexive textual practices in organization and management theory", Journal of Management Studies, 45(39:480-501.

Finlay, L (2008) "The reflexive journey: mapping multiple routes", pp. 3-20 in Finlay, L \& Gough, B (eds), Reflexivity: a practical guide for researchers in health and social sciences. Oxford: Blackwell Science.

Gough, B (2008) “Deconstructing reflexivity”, pp. 21-35 in Finlay, L \& Gough, B (eds), Reflexivity: a practical guide for researchers in health and social sciences. Oxford: Blackwell Science.

Kuehner, A, Ploder, A, Langer, P C (2016). “Introduction to special issue European contributions to strong reflexivity", Qualitative Inquiry, 22(9).

Lynch, M (2000) "Against reflexivity as an academic virtue and source of privileged knowledge", Theory, Culture \& Society, 17(3).

MacBeth, Douglas (2001). "On 'reflexivity' in qualitative research: two readings, and a third", Qualitative Inquiry, 7(1).

Wilkinson, S (1988). "The role of reflexivity in feminist psychology", Women's Studies International Forum, 11(5), 493-502. 